Check for updates

Cite this: Sustainable Energy Fuels, 2017, 1, 780

Received 10th February 2017

Accepted 11th April 2017

DOI: $10.1039 / \mathrm{c} 7 \mathrm{se} 00086 \mathrm{c}$

rsc.li/sustainable-energy

\title{
Template-free synthesis of mesoporous manganese oxides with catalytic activity in the oxygen evolution reaction $\uparrow$
}

\author{
Suoyuan Lian, $\sharp^{a}$ Michelle P. Browne, $\$^{a}$ Carlota Domínguez, ${ }^{a}$ Serban N. Stamatin, ${ }^{a}$ \\ Hugo Nolan, ${ }^{a}$ Georg S. Duesberg, ${ }^{a}$ Michael E. G. Lyons, (D) ${ }^{a}$ Emiliano Fondab \\ and Paula E. Colavita (D)*a
}

\begin{abstract}
Porous manganese carbonate was obtained via solvothermal synthesis using ethanol and urea. The manganese carbonate was subsequently used as a precursor to synthesise mesoporous manganese oxides via thermal treatments at three various temperatures. X-ray diffraction and Extended $\mathrm{X}$-ray Absorption Fine Structure (EXAFS) results shows that $\gamma-\mathrm{MnO}_{2}$ is synthesised at 380 and $450{ }^{\circ} \mathrm{C}$ while $\mathrm{Mn}_{2} \mathrm{O}_{3}$ is produced at the annealing temperature of $575^{\circ} \mathrm{C}$. X-ray absorption spectra show that $\gamma-\mathrm{MnO}_{2}$ converts completely to $\mathrm{Mn}_{2} \mathrm{O}_{3}$ after annealing over the $450-575{ }^{\circ} \mathrm{C}$ range. The oxides obtained at $380{ }^{\circ} \mathrm{C}$ and $450{ }^{\circ} \mathrm{C}$ possess extremely high specific surface area, which is of interest for catalytic applications. The oxides were investigated as electrocatalysts for the oxygen evolution reaction; the oxide prepared at the lowest annealing temperature was found to be the optimum catalyst with an overpotential of $427 \pm 10 \mathrm{mV}$ at a current density of $10 \mathrm{~mA} \mathrm{~cm}{ }^{-2}$, normalised by the geometric area. The improved catalytic activity was related to the presence of defect-rich and highly porous manganese dioxide at the lowest annealing temperature.
\end{abstract}

\section{Introduction}

It is estimated that the world's current fossil fuel reserve will be depleted within the next century, therefore alternative routes to the production of energy are urgently needed and further integration of renewable sources into the energy economy will be necessary over the next decades. ${ }^{1,2}$ Alkaline water electrolysis, when coupled with renewable sources, can provide a clean and environmentally friendly path for the production of $\mathrm{H}_{2}$, an alternative fuel. ${ }^{3,4}$ Fuel cells that use $\mathrm{H}_{2}$ and $\mathrm{O}_{2}$ can produce electric power on demand to supply the national grid or to power car transport, with the major advantage to this energy route that emissions are limited to water. ${ }^{5,6}$ Unfortunately, most of the $\mathrm{H}_{2}$ currently used in fuel cells is generated by steam reforming of fossil fuels, while the percentage that comes directly from water electrolysis only accounts for $4 \% .{ }^{7,8}$ Since the discovery of water electrolysis by van Troostwijk and Deiman, the technology of water electrolysis has indeed been

\footnotetext{
${ }^{a}$ School of Chemistry, CRANN and AMBER Research Centres, Trinity College Dublin, College Green, Dublin 2, Ireland. E-mail: colavitp@tcd.ie

${ }^{b}$ Synchrotron SOLEIL L'Orme de Merisiers, St Aubin BP48, 91192 Gif sur Yvette Cedex, France

$\dagger$ Electronic supplementary information (ESI) available: Further characterisation data including an image of $\mathrm{MnO}_{x}$ powders, Raman, XAS, XRD and LSVs. See DOI: $10.1039 / \mathrm{c} 7 \mathrm{se} 00086 \mathrm{c}$

\$ Joint first author.
}

commercially developed, but is economically limited by the rare and expensive materials needed as electrocatalysts., ${ }^{9,10}$

Water electrolysis results in the formation of $\mathrm{O}_{2}$ at the anode, via the oxygen evolution reaction (OER), and of $\mathrm{H}_{2}$ at the cathode. Even though the main goal for energy applications is to generate $\mathrm{H}_{2}$ at the cathode, the majority of research efforts concentrate on the anodic reaction. The OER is the rate determining step of water electrolysis which also makes it the most energy demanding electrode process; therefore, a reduction in the OER overpotential can translate into greater efficiency in hydrogen production. ${ }^{6}$ To date, $\mathrm{RuO}_{2}$ is regarded as the most active OER catalyst in alkaline media as this oxide catalyses water oxidation at the lowest known overpotentials at a current density of $10 \mathrm{~mA} \mathrm{~cm}{ }^{-2} .^{11,12}$ However, its commercial application is limited owing to its high cost and low abundance. ${ }^{13}$

Transition metal oxides (TMOs), from the first row of the periodic table, in particular $\mathrm{Mn}, \mathrm{Fe}$, $\mathrm{Co}$ and $\mathrm{Ni}$ oxides, are viable candidates to replace $\mathrm{IrO}_{2}$ and $\mathrm{RuO}_{2}$ as OER catalysts. ${ }^{14,15}$ Currently in literature, a vast number of reports on water oxidation focus on applications of nickel, cobalt and iron oxides as electrocatalysts; however, there has been a recent increased interest in investigating manganese oxides as catalysts for the OER. $^{2,16-29}$ Some of the reported OER activities of manganese oxides in literature are extremely encouraging. ${ }^{11,30-33}$ Suib et al. studied the OER capabilities of three phases of $\mathrm{MnO}_{2}, \alpha, \beta$ and $\gamma$, on a carbon support that were fabricated through three similar hydrothermal routes. The overpotential at $10 \mathrm{~mA} \mathrm{~cm}^{-2}$ for the $\alpha$, 
$\beta$ and $\gamma$ phases were $0.49,0.60$ and $0.74 \mathrm{~V}$, respectively. ${ }^{30}$ These results indicate that small changes in the synthetic method alter the resulting phase and the OER activity. Commercial MnO, $\mathrm{Mn}_{3} \mathrm{O}_{4}, \mathrm{Mn}_{2} \mathrm{O}_{3}$ and $\mathrm{MnO}_{2}$ powder samples, made into an ink dispersion, were deposited onto a glassy carbon substrate and tested as OER catalysts by Jaramillo et $a .^{34}$ The overpotentials of $0.51,0.43,0.53$ and $0.5 \mathrm{~V}$ were reached to obtain a current density of $10 \mathrm{~mA} \mathrm{~cm}{ }^{-2}$ for the $\mathrm{MnO}, \mathrm{Mn}_{3} \mathrm{O}_{4}, \mathrm{Mn}_{2} \mathrm{O}_{3}$ and $\mathrm{MnO}_{2}$, respectively. Interestingly, Fiechter et al. fabricated $\mathrm{Mn}_{3} \mathrm{O}_{4}$ and $\mathrm{Mn}_{2} \mathrm{O}_{3}$ by an electrodeposition/thermal process. ${ }^{35}$ This study showed that the $\mathrm{Mn}_{2} \mathrm{O}_{3}$ was a superior OER catalyst when compared to $\mathrm{Mn}_{3} \mathrm{O}_{4}$, which contradicted the previous report by Jaramillo et al. ${ }^{34,35}$ Additionally the $\mathrm{MnO}_{2}$ materials produced by Jaramillo et al. and Suib et al. also exhibited varying overpotential values at $10 \mathrm{~mA} \mathrm{~cm}^{-2}$. Therefore, the specific fabrication process used to synthesise the Mn oxide clearly plays a critical role in determining the activity of the material for the OER.

The physical structure of the OER catalysts, such as shape or surface area, strongly affects their performance. ${ }^{19,36-38}$ The surface area of a material has been previously linked to an increase in the OER catalytic activity of metal oxides due to the potential increased density of active sites. ${ }^{39}$ Solvothermal synthesis can be used to fabricate porous materials, ${ }^{40}$ most notably using soft or hard templates; ${ }^{\mathbf{4 1 , 4 2}}$ however, the templates required for the formation of porous products must be etched post synthesis and this removal stage is time consuming and adds to the complexity of the process. A solution to this consists of using precursors that decompose into gaseous products so that gas bubbles template pore formation during the synthesis. Lian et al., has previously used urea as a precipitant for the formation of metal hydroxides and after annealing, a porous structure remains. ${ }^{43}$ Precipitants such as urea or $\mathrm{NH}_{4} \mathrm{HCO}_{3}$ are routinely used under hydrothermal conditions however in this study urea will be used under solvothermal conditions. ${ }^{\text {43-46 }}$

Synthesis of Mn oxides for OER applications via solvothermal methods is relatively underexplored compared to electrochemical and thermal methods. ${ }^{19,28,31,35,47}$ In this work, porous $\mathrm{MnCO}_{3}$ was synthesised by a template free solvothermal-urea method; urea was used as the precipitant and ethanol as the solvent under solvothermal conditions. Solvothermal conditions were preferred over hydrothermal conditions as ethanol results in higher pressure in a closed reactor compared to water at the same temperature, which was expected to promote porosity in the carbonate material. The resulting $\mathrm{MnCO}_{3}$ was used as a precursor for the subsequent preparation of Mn oxides via thermal decomposition at different temperatures. The materials were characterised by a variety of techniques to determine composition, morphology, and surface area. Voltammetry experiments in alkaline media show that the synthesised oxides are active in the OER; trends in onset potential are interpreted and discussed in relation to the structural and morphological properties.

\section{Experimental methods}

\section{Chemicals and materials}

Manganese acetate ( $\geq 99 \%$ metal basis), sodium hydroxide pellets ( $\geq 98 \%$, reagent-grade), urea and Nafion-117 (reagent- grade) were purchased from Sigma and used without further purification; ethanol (reagent grade, >99\%) was purchased from the TCD solvent facility.

\section{Synthesis}

In a typical synthesis, $0.30 \mathrm{~g} \mathrm{Mn}\left(\mathrm{CH}_{3} \mathrm{COO}\right)_{2} \cdot 6 \mathrm{H}_{2} \mathrm{O}, 0.35 \mathrm{~g}$ urea and $11 \mathrm{~mL}$ ethanol were mixed together directly in an $18 \mathrm{~mL}$ Teflon-lined stainless steel autoclave (Yuhua Instrument CO., LTD). The autoclave was sealed and placed inside the oven and heated at $140{ }^{\circ} \mathrm{C}, 160{ }^{\circ} \mathrm{C}$ or $180{ }^{\circ} \mathrm{C}$ for $24 \mathrm{~h}$. After the reaction time, the autoclave was allowed to cool to room temperature under natural convection. Samples were centrifuged and washed alternately in ethanol and Millipore water, 4 times, and finally dried at $50{ }^{\circ} \mathrm{C}$ for $12 \mathrm{~h}$. Annealing of the resulting $\mathrm{MnCO}_{3}$ was carried out at 380,450 and $575{ }^{\circ} \mathrm{C}$ for $4 \mathrm{~h}$ in a tube furnace in air and the resulting $\mathrm{MnO}_{x}$ were denoted as $\mathrm{Mn}-380, \mathrm{Mn}-450$, Mn-575, respectively.

\section{Characterisation}

Emission Scanning Electron Microscope (SEM) was carried out using a Karl Zeiss Ultra Field Emission Scanning Electron Microscope (SEM) at $5 \mathrm{kV}$ accelerating voltage and $5 \mathrm{~mm}$ working distance using a Secondary Electron (SE) detector. Transmission Electron Microscopy (TEM) was performed using a JEOL JEM-2100 TEM at an accelerating voltage of $200 \mathrm{kV}$; samples were mounted on holey carbon/copper grids (S147, Agar Scientific). Powder X-ray diffraction (XRD) patterns were collected in a Bruker D2 Phaser with a $\mathrm{Cu} K \alpha$ source $(\lambda=1.5418$ $\AA)$. Specific surface area measurements were carried out on a Quantachrome Autosorb iQ, running nitrogen physisorption measurements at $77 \mathrm{~K}$. Thermogravimetric analysis (TGA) was conducted on a Pyris 1 Thermogravimetric Analyzer (PerkinElmer) with a $5{ }^{\circ} \mathrm{C} \min ^{-1}$ temperature ramp, using air as carrier gas. Raman spectroscopy measurements were performed using a Witec alpha 300R confocal Raman microscope using a 1800 line $\mathrm{mm}^{-1}$ grating and a $532 \mathrm{~nm}$ diode laser at an incident power of $<10 \mathrm{~mW}$ and a spot size of $300 \mathrm{~nm}$.

$\mathrm{X}$-ray absorption near edge structure (XANES) and Extended Xray Absorption Fine Structure (EXAFS) measurements were undertaken at the SAMBA beamline at SOLEIL synchrotron, France. ${ }^{48}$ Pellets were fabricated using cellulose and $6 \mathrm{wt} \%$ of the relevant Mn material then mounted in a holder for analysis; all pellets were measured in transmittance mode at the Mn K-edge. Reference samples (purchased from Sigma) of MnO (manganosite), $\mathrm{Mn}_{3} \mathrm{O}_{4}$ (hausmannite), $\alpha-\mathrm{Mn}_{2} \mathrm{O}_{3}$ and $\beta-\mathrm{MnO}_{2}$ were recorded in addition to synthesised samples for the analysis of edge positions. All samples were calibrated using a Mn foil during the experiments. Data analysis was performed using Athena and Artemis software packages; ${ }^{\mathbf{4 9}}$ calculation of scattering paths was carried out using FEFF v.8.4 and self-consistent potentials. ${ }^{50}$ EXAFS data was extracted as described by Newville et al. ${ }^{51}$ with a $R_{\mathrm{bkg}}=1$. The Fourier Transform (FT) was performed between $k=$ 3 and $10.5 \AA^{-1}$ with a Hanning apodization window with sills of amplitude $\mathrm{d} k=1$. The EXAFS signal was weighted by $k^{3}$ and fitted in $r$-space between 1 and $4 \AA$ A; both real and imaginary parts were fitted according to the procedure described by Newville. ${ }^{52}$ 


\section{Electrochemical measurements}

All electrochemical experiments were carried out in a standard three-electrode cell using a high performance digital potentiostat ( $\mathrm{CH}$ model $1760 \mathrm{D}$ Bi-potentiostat). A graphitic carbon rod was used as counter electrode. The potential was recorded using an $\mathrm{Hg} / \mathrm{HgO}$ reference electrode ( $\mathrm{CH}$ instruments, \#152); all potentials are reported $v s$. the reversible hydrogen electrode based on the following equation: $E_{\mathrm{RHE}}=E_{\mathrm{HgO} / \mathrm{Hg}}+0.059(\mathrm{pH})+$ $0.098 \mathrm{~V}$. The working electrode (WE) consisted of ITO glass (7 ohm per sq, Xin Yan Technology Ltd.) on which the relevant solvothermal material was deposited from an ink dispersion. The inks were prepared as follows: $10 \mathrm{mg}$ of manganesecontaining powders were mixed with $8 \mu \mathrm{L}$ of Nafion solution and $400 \mu \mathrm{L}$ ethanol, followed by sonication for $1 \mathrm{~h} .20 \mu \mathrm{L}$ of the dispersion was then dropped onto the ITO glass over a $7 \times 7$ $\mathrm{mm}^{2}$ surface area defined by masking tape resulting in a $1 \mathrm{mg}$ $\mathrm{cm}^{-2}$ loading for all samples; current densities were calculated based on the geometric area defined by the mask. Linear sweep voltammetry (LSV) was conducted in $1 \mathrm{M} \mathrm{NaOH}$ solution at a scan rate of $5 \mathrm{mV} \mathrm{s}^{-1}$ in the anodic direction. All measurements were conducted at a constant temperature of $25^{\circ} \mathrm{C}$, using a thermal bath with the temperature maintained by a thermostat. All plotted data are presented in iR compensated form; the iR compensation was calculated from a built-in iR compensation module in the $\mathrm{CH}$-instrument software.

\section{Results and discussion}

The solvothermal synthesis of manganese carbonate $\left(\mathrm{MnCO}_{3}\right)$ from the acetate in the presence of urea was carried out at 140, 160 and $180^{\circ} \mathrm{C}$ in order to determine at what temperature the pure carbonate is obtained. The colors of the powders obtained at the three temperatures, Fig. $\mathrm{S} 1, \uparrow$ are different, whereby the solids formed at 140,160 and $180{ }^{\circ} \mathrm{C}$ were brown, light brown and white, respectively. After synthesis, X-ray diffraction (XRD) was performed on all of the samples, Fig. 1a. XRD analysis reveals that solids prepared at $140{ }^{\circ} \mathrm{C}$ display reflections from both $\mathrm{MnCO}_{3}$ and $\mathrm{Mn}_{3} \mathrm{O}_{4}$ (COD: 9007691 and COD: 9001302). After increasing the temperature to $160{ }^{\circ} \mathrm{C}$, the $\mathrm{Mn}_{3} \mathrm{O}_{4}$ reflections are less visible, indicating that the $\mathrm{Mn}_{3} \mathrm{O}_{4}$ decomposes and the $\mathrm{MnCO}_{3}$ becomes the major component. At $180{ }^{\circ} \mathrm{C}$, the results show that the powder is completely composed of $\mathrm{MnCO}_{3}$. Brunauer Emmett Teller (BET) analysis of nitrogen adsorption isotherms for samples prepared at $180{ }^{\circ} \mathrm{C}$ yielded a specific surface area of $100 \mathrm{~m}^{2} \mathrm{~g}^{-1}$; thus indicating that the synthesis in the presence of urea results in a porous solid.

Thermogravimetric analysis (TGA) was also performed on the three synthesised $\mathrm{MnCO}_{3}$ to investigate phase changes during the thermal treatment in air to determine which powder would be the best precursor for producing metal oxides, Fig. $1 \mathrm{~b}$. The loss of mass in the temperature region of $0-220{ }^{\circ} \mathrm{C}$ can be attributed to the loss of approximately $5 \%$ of water for all the $\mathrm{MnCO}_{3}$ powders. At $220{ }^{\circ} \mathrm{C}$, the $\mathrm{MnCO}_{3}$ is known to decompose to form $\mathrm{MnO}_{2}$ as discussed by Zhu et al. ${ }^{53}$ For the sample prepared at $180{ }^{\circ} \mathrm{C}$, the weight loss, after accounting for the loss of water, is approximately $31 \%$, which is in agreement with
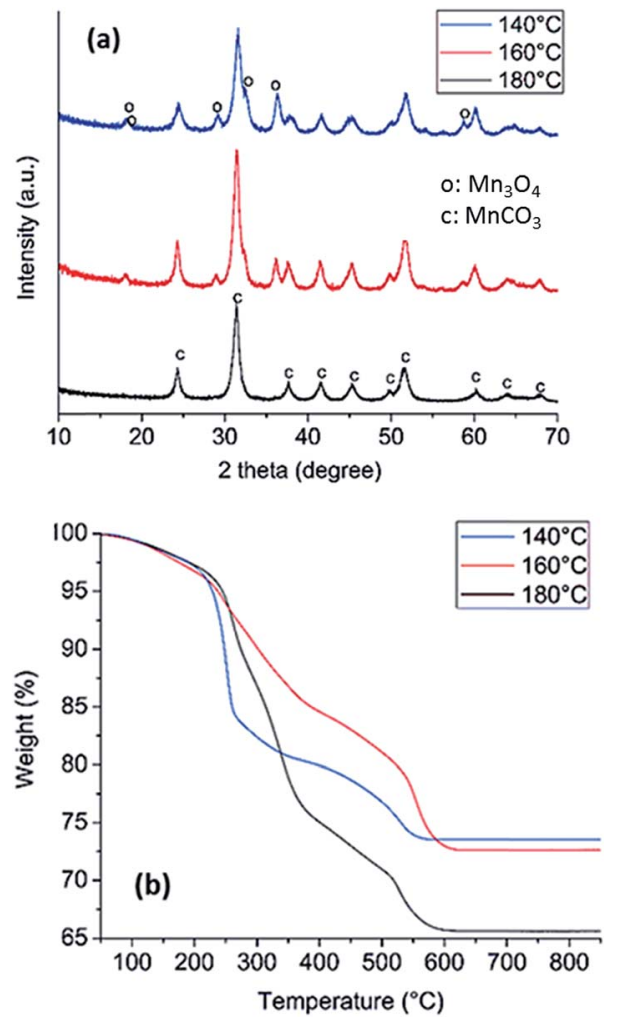

Fig. 1 XRD (a) and TGA (b) of solid samples prepared from the solvothermal reaction of manganese acetate in the presence of urea at three different temperatures. Diffraction peaks associated to $\mathrm{Mn}_{3} \mathrm{O}_{4}$ (o) and to $\mathrm{MnCO}_{3}$ (c) are labeled in (a).

a transition from $\mathrm{MnCO}_{3}$ to $\mathrm{Mn}_{2} \mathrm{O}_{3} \cdot{ }^{54}$ The samples prepared at $160{ }^{\circ} \mathrm{C}$ and $140{ }^{\circ} \mathrm{C}$ have a lower weight loss of $24 \%$ and $23 \%$, which suggests the co-existence of lower Mn oxide species after thermal treatment, likely associated with the presence of $\mathrm{Mn}_{3} \mathrm{O}_{4}$ identified in the XRD of the starting sample (Fig. 1a). The significant weight loss resulting from decomposition of the sample prepared at $180{ }^{\circ} \mathrm{C}$ indicates that this is the precursor compound that results in the greatest gas evolution, thus suggesting potential for high porosity upon thermal treatment. Since high specific surface area is a desirable property for applications in catalysis, the $\mathrm{MnCO}_{3}$ synthesised at $180^{\circ} \mathrm{C}$ was henceforth chosen as the precursor for the formation of the $\mathrm{Mn}$ oxide catalysts for OER.

\section{Characterisation of oxides obtained from $\mathrm{MnCO}_{3}$ precursor}

The $\mathrm{MnCO}_{3}$ was further annealed in air at 380,450 and $575{ }^{\circ} \mathrm{C}$ to produce different oxide materials, denoted Mn-380, Mn-450 and $\mathrm{Mn}-575$, for testing in the OER. The resulting oxides and the $\mathrm{MnCO}_{3}$ precursor were characterised in terms of porosity, morphology and structure using a combination of nitrogen adsorption analysis, scanning and transmission electron microscopy (SEM, TEM), XRD and X-ray absorption spectroscopy (XAS).

Nitrogen adsorption/desorption isotherms were analysed to determine specific surface area and pore size distribution of the $\mathrm{MnCO}_{3}$ precursor and of the oxides obtained after thermal 
treatment in air, Fig. 2 and Table 1. Fig. 2a, shows that all samples display characteristic type-IV adsorption isotherms. ${ }^{55}$ The specific surface areas calculated using the BET method are reported in Table 1; results indicate that the carbonate precursor has an initially high porosity of $100 \mathrm{~m}^{2} \mathrm{~g}^{-1}$ which is high compared to a previously reported commercial $\mathrm{MnCO}_{3}$ sample with a value of $11.3 \mathrm{~m}^{2} \mathrm{~g}^{-1}$ and to some of the recently reported porous $\mathrm{MnCO}_{3} \cdot{ }^{53,56}$ After thermal treatment, the materials formed remain highly porous after annealing treatments at 380 and $450{ }^{\circ} \mathrm{C}$, while the surface area collapses after annealing at $575{ }^{\circ} \mathrm{C}$. The BET surface areas of the Mn-380 and the Mn-450 materials are significantly higher than those typically reported in literature for $\mathrm{Mn}$ oxides from thermal decomposition of $\mathrm{MnCO}_{3} \cdot{ }^{57,58}$ The pore size distribution of all samples obtained via Barrett-Joyner-Halenda (BJH) analysis of desorption branches can be observed in Fig. 2b. For the asprepared $\mathrm{MnCO}_{3}$, the pore size is predominately in the range of $1.5-2.5 \mathrm{~nm}$, while after annealing at 380,450 or $575{ }^{\circ} \mathrm{C}$, a maximum in the pore size distribution develops in the range 3-10 $\mathrm{nm}$; this indicates that gas evolution after thermal treatment of $\mathrm{MnCO}_{3}$ leads to the opening of pores in the mesopore range. The use of ethanol as the solvent was crucial for the development of a porous structure in $\mathrm{MnCO}_{3}$, as shown by the synthesis of $\mathrm{MnCO}_{3}$ using hydrothermal conditions. Fig. 2a and $\mathrm{b}$ show the adsorption/desorption isotherms and $\mathrm{BJH}$ pore
Table 1 Specific surface area of precursor $\mathrm{MnCO}_{3}$ and of samples after thermal annealing in air at 380,450 and $575^{\circ} \mathrm{C}$

\begin{tabular}{ll}
\hline Sample & $\begin{array}{l}\text { BET area } \\
\left(\mathrm{m}^{2} \mathrm{~g}^{-1}\right)\end{array}$ \\
\hline $\mathrm{MnCO}_{3}$ & 100 \\
$\mathrm{Mn}-380$ & 109 \\
$\mathrm{Mn}-450$ & 101 \\
$\mathrm{Mn}-575$ & 48 \\
Hydrothermal & 9.7 \\
\hline
\end{tabular}

distribution, respectively, of the hydrothermal precursor. Almost no hysteresis loop is observed in Fig. 2a suggesting that no porous structure forms during the hydrothermal process of the same materials, and the BET surface area was $90 \%$ lower than that obtained under solvothermal conditions.

All of the materials after the annealing treatment were comprised of sheets or particles which group together to form spherical structures, Fig. 2c-e. After the preparation of the dispersion via sonication the spherical structures are disrupted resulting in solid particles that could be deposited onto solid surfaces, as shown in Fig. $2 \mathrm{f}-\mathrm{h}$. There was no apparent variation observed in the morphology of the Mn-380 and Mn-450 samples whereas particles in the Mn-575 appear smaller when compared to the lower annealing temperatures.

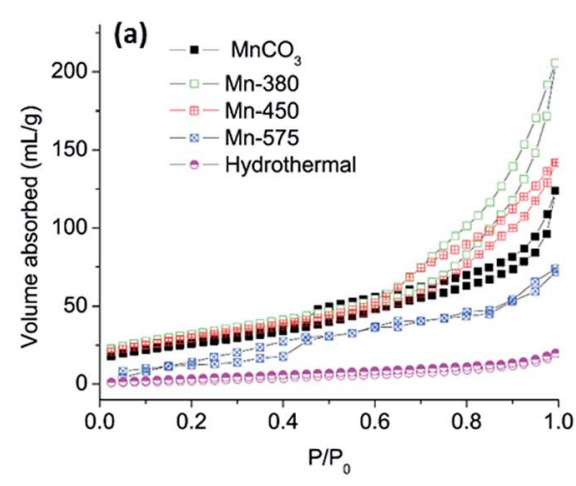

(c)

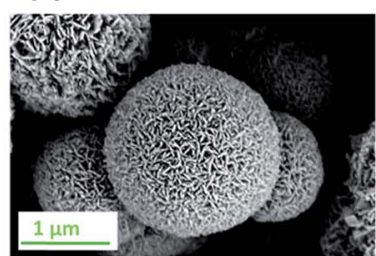

(f)

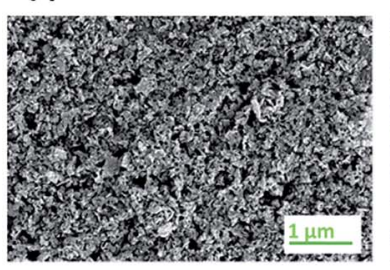

(d)

(g)
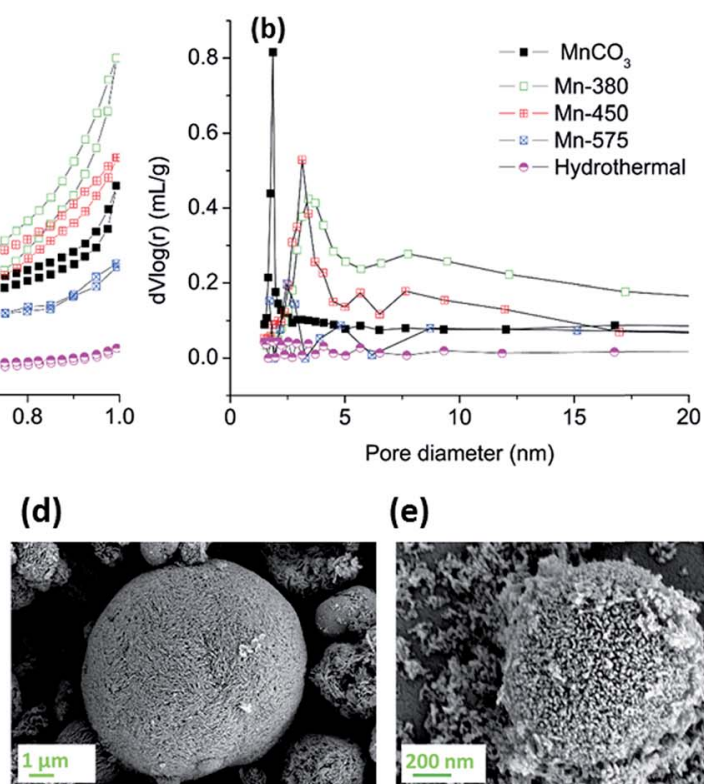

(e)

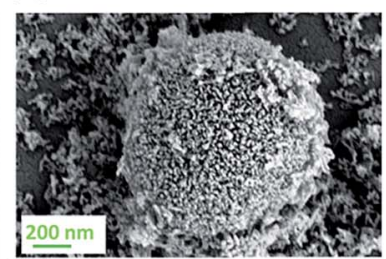

(h)

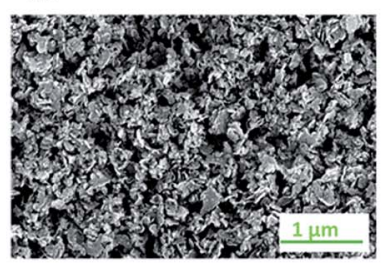

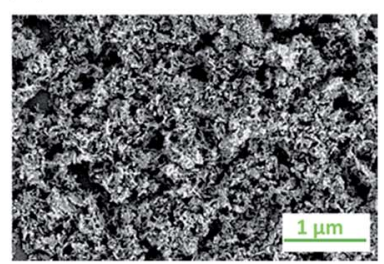

Fig. 2 (a) Nitrogen adsorption/desorption isotherms and (b) BJH pore size distribution diagram of MnCO $3, \mathrm{Mn}-380, \mathrm{Mn}-450$ and Mn-575 (c) SEM image of as-prepared Mn-380 (d) SEM image of as-prepared Mn-450 (e) SEM image of as-prepared Mn-575 and (f) SEM image of Mn-380 as a film, (g) SEM image of Mn-450 and (h) SEM image of Mn-575. 
Changes in particle morphology were further investigated via TEM; Fig. 3a-d show images of the $\mathrm{MnCO}_{3}$ precursor and the Mn-380, Mn-450 and Mn-575 powders. Before any heat treatment to the $\mathrm{MnCO}_{3}$, the solid particles display a nanosheet-like morphology, Fig. 3a, with the size of these $\mathrm{MnCO}_{3}$ nanosheets in the range $100-200 \mathrm{~nm}$. After thermal treatment at 380 and $450{ }^{\circ} \mathrm{C}$, a sheet-like morphology is still present the $\mathrm{MnCO}_{3}$ precursor particles. After thermal treatment at $575{ }^{\circ} \mathrm{C}$ a significant change in morphology is observed, whereby particles appear to be denser.

The XRD patterns of the precursor $\mathrm{MnCO}_{3}$ and of the compounds obtained after thermal treatment at 380, 450 and $575{ }^{\circ} \mathrm{C}$ are shown in Fig. 4a. Upon increasing annealing temperature it can be observed that the XRD pattern is dramatically altered from the $\mathrm{MnCO}_{3}$ starting material. For the $\mathrm{MnCO}_{3}$, all peaks can be indexed to a standard $\mathrm{MnCO}_{3}$ (COD: 9007691) as previously discussed. The sample treated at the lowest temperature of $380{ }^{\circ} \mathrm{C}$ exhibits broad peaks that are in agreement with those reported for electrolytic manganese dioxides (EMD), Fig. 4b. ${ }^{61}$ EMD is proposed to be composed of both $\varepsilon-\mathrm{MnO}_{2}$ and $\gamma-\mathrm{MnO}_{2}$, however $\gamma-\mathrm{MnO}_{2}$ is the predominant phase. ${ }^{61}$ The reflections at $23.0^{\circ}, 37.0^{\circ}, 42.1^{\circ}, 55.2^{\circ}$ and $66.3^{\circ}$ are in agreement with the EMD structure studied by Simon et al. ${ }^{61}$ while an additional broad peak at $31.4^{\circ}$ can be attributed to the starting material, $\mathrm{MnCO}_{3}$. Raman analysis of the $\mathrm{Mn}-380$ sample (see ESI $\dagger$ ) also indicates that a phase of $\mathrm{MnO}_{2}$ is present, Fig. S2; $\dagger$ the intense peak at $661 \mathrm{~cm}^{-1}$ can be attributed to $\varepsilon-\mathrm{MnO}_{2}$ in agreement with results reported by Lin et al. ${ }^{60,61}$ After thermal treatment at $450{ }^{\circ} \mathrm{C}$, the XRD pattern displays similar reflections to those of $\mathrm{Mn}-380$, while additional peaks consistent with the presence of $\mathrm{Mn}_{2} \mathrm{O}_{3}$ are also evident at $33.0^{\circ}$, $55.2^{\circ}$ and $65.8^{\circ}$, Fig. $4 \mathrm{c} .{ }^{19}$ After treatment at $575{ }^{\circ} \mathrm{C}$ the XRD pattern displays narrow peaks, Fig. $4 \mathrm{~d}$, that can all be indexed to standard $\mathrm{Mn}_{2} \mathrm{O}_{3}$ (COD: 9007520), thus indicating the complete conversion of the material to pure $\mathrm{Mn}_{2} \mathrm{O}_{3}$ oxide phase. The Raman spectrum for Mn-575 also confirms a change in the oxide structure, with peaks in agreement with those observed for $\mathrm{Mn}_{2} \mathrm{O}_{3}$ by Julien et al. ${ }^{62}$

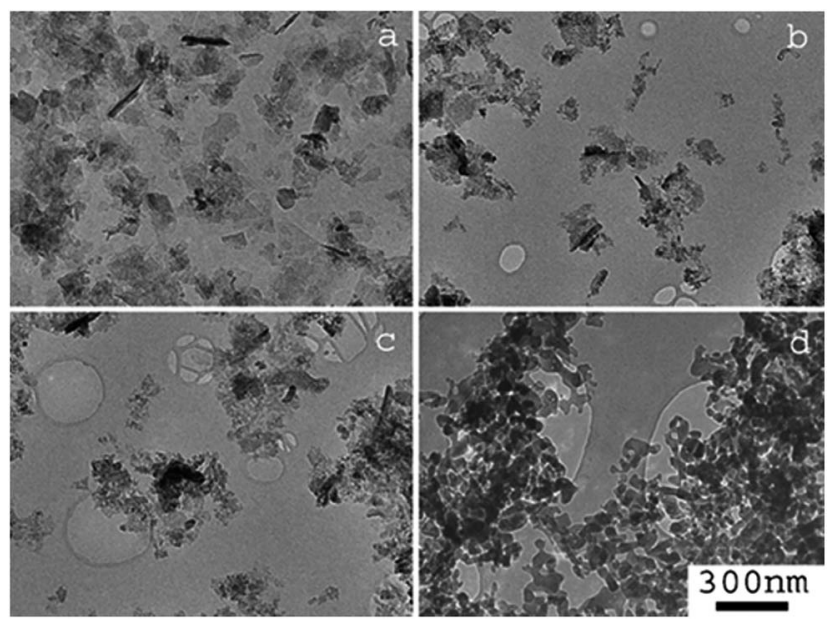

Fig. 3 TEM images of (a) $\mathrm{MnCO}_{3}$, (b) $\mathrm{Mn}-380$ (c) $\mathrm{Mn}-450$ and (d) $\mathrm{Mn}-$ 575. Scale bar for all images is shown in (d).
The presence of broad peaks and mixed phases in XRD patterns indicates that materials obtained from the thermal decomposition of $\mathrm{MnCO}_{3}$ in air possess low crystallinity and are structurally disordered. XAS was therefore used to characterise $\mathrm{MnCO}_{3}$ and $\mathrm{MnO}_{x}$ powders. Normalised absorption spectra at the Mn K-edge for $\mathrm{MnCO}_{3}, \mathrm{Mn}-380, \mathrm{Mn}-450$ and $\mathrm{Mn}-575$ samples are shown in Fig. 5a. The absorption edge energy of Mn-380 and Mn-450 is higher than that of Mn-575, thus indicating that Mn-centres in $\mathrm{MnO}_{x}$ powders synthesised at 380 and $450{ }^{\circ} \mathrm{C}$ have a higher average oxidation state than in the $\mathrm{MnO}_{x}$ powder annealed at $575{ }^{\circ} \mathrm{C} .{ }^{63} \mathrm{~A}$ comparison with the precursor $\mathrm{MnCO}_{3}$ sample also shows that in all cases the oxidation state is higher than that in the carbonate precursor. The normalised Xray absorption near edge (XANES) spectra of Mn-380 and Mn450 samples are indistinguishable thus indicating that their structure is similar, in agreement with XRD results. The XANES of Mn-575 samples was found to match that of $\mathrm{Mn}_{2} \mathrm{O}_{3}$, as shown in Fig. 5b, also confirming the XRD assignments. The Mn-380 sample could not be fitted through a combination of any of the reference samples tested and its structure was determined via further analysis of the extended X-ray absorption fine structure (EXAFS) spectrum as discussed below.

To confirm the presence of $\varepsilon-\mathrm{MnO}_{2}$ and/or $\gamma-\mathrm{MnO}_{2}$ in $\mathrm{Mn}$ 380 suggested by the XRD pattern, the EXAFS spectrum was fitted in $R$ space, Fig. 5c; the fit presented includes only single scattering contributions up to $4 \AA$ and was obtained by fixing $S_{0}{ }^{2}$ at 0.8. The positions and amplitudes of the main peaks in the best fit match the coordination number $(N)$ and distances $(R)$ of the $\mathrm{Mn}-\mathrm{O}(1), \mathrm{Mn}-\mathrm{Mn}(1), \mathrm{Mn}-\mathrm{O}(2)$ and $\mathrm{Mn}-\mathrm{Mn}(2)$ coordination shells of $\gamma-\mathrm{MnO}_{2}$. The scattering path parameters $N$ and $R$ obtained for the best fit of Mn-380 can be observed in Table 2 and are in excellent agreement with those reported by Godart $e t$ al. for $\gamma-\mathrm{MnO}_{2} ;{ }^{64}$ the mean-square displacements are relatively large and indicate significant disorder in the oxide structure. Fits which included coordination shells characteristic of $\varepsilon^{-}$ $\mathrm{MnO}_{2}$ resulted in a significant reduction in the goodness of fit (see ESI, Fig. S3†). In summary, XAS results show that Mn-380 and $\mathrm{Mn}-450$ samples consist of predominantly $\gamma-\mathrm{MnO}_{2}$, whereas Mn-575 samples mainly consist of $\mathrm{Mn}_{2} \mathrm{O}_{3}$.

\section{OER performance of manganese oxides}

The linear sweep voltammetry (LSV) curves for the precursor $\mathrm{MnCO}_{3}$ and the various Mn oxides can be observed in Fig. 6; LSV curves plotted as a function of overpotential are reported in the ESI. $\dagger$ The three $\mathrm{MnO}_{x}$ samples show enhanced OER activity when compared with the $\mathrm{MnCO}_{3}$ as all three oxide materials yield higher anodic currents when compared to the $\mathrm{MnCO}_{3}$. In current literature, the activities of OER materials are ranked by how low the overpotential value is at a current density of $10 \mathrm{~mA}$ $\mathrm{cm}^{-2}$. The reporting of the overpotential values at a current density of $10 \mathrm{~mA} \mathrm{~cm}{ }^{-2}$ is related to the energy produced for the utilisation of a water electrolyser linked to a $10 \%$ efficient solar cell and is the most common figure of merit when comparing OER catalysts. ${ }^{11,18,19,31}$

The Mn-380 exhibits the highest activity for OER and the overpotential $(\eta)$ at a current density of $10 \mathrm{~mA} \mathrm{~cm}^{-2}$ is $427 \pm$ 

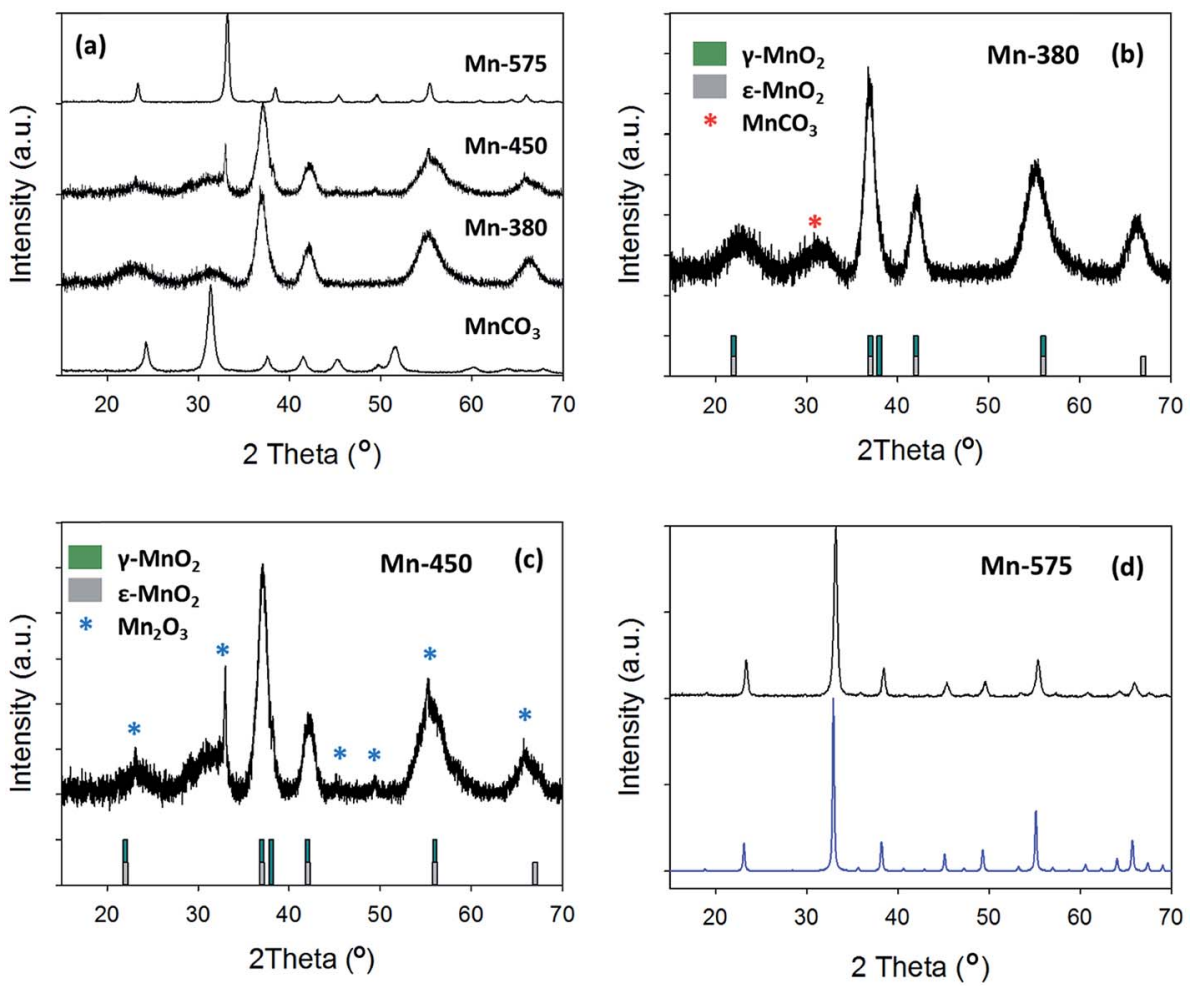

Fig. 4 (a) XRD pattern of $\mathrm{MnCO}_{3}, \mathrm{Mn}-380, \mathrm{Mn}-450$ and $\mathrm{Mn}-575$; (b) $\mathrm{Mn}-380$ and (c) $\mathrm{Mn}-450$ compared to $\gamma-\mathrm{MnO}_{2}$ and $\varepsilon-\mathrm{MnO}_{2}$ patterns from literature:59,60 (d) $\mathrm{Mn}-575$ compared to COD reference for $\mathrm{Mn}_{2} \mathrm{O}_{3}$ (COD: 9007520).

$10 \mathrm{mV}$. The overpotentials at the same current density for the Mn-450 and Mn-575 materials are $470 \pm 10 \mathrm{mV}$ and $570 \pm$ $20 \mathrm{mV}$, respectively. The $\mathrm{MnCO}_{3}$ starting material proves to be very inactive for the OER as it only reaches a current density of approximately $0.72 \mathrm{~mA} \mathrm{~cm}{ }^{-2}$ at the overpotential of $570 \mathrm{mV}$. The relative order of activity is the same also when the current density is normalized by the BET area of each material (see Fig. S5 $\dagger$ ). This result indicates that the annealing step is a critical step in this study. The overpotentials were found to be constant over three cycles for all materials; however stability over prolonged cycling was limited by physical spalling during OER due to low adhesion between the ITO support and the oxide. This suggests that mechanical stability of the supported particles must be optimised for future device applications, as previously noted for other OER catalysts. ${ }^{65}$

The improved performance of the Mn-380 is likely related to the specific oxide phase and/or the increased surface area of this material. The structure of the sample is consistent with that observed for highly disordered $\mathrm{MnO}_{2}$ phases, based on both XRD and XAS. The Mn-O(1) distance is typical of $\mathrm{Mn}(\mathrm{Iv}) / \mathrm{Mn}$ (III) oxides, ${ }^{17}$ while the $\mathrm{Mn}-\mathrm{Mn}(1)$ distance indicates the presence of edge-sharing $\mathrm{MnO}_{6}$ octahedra, often associated with catalytically active $\mathrm{MnO}_{x}{ }^{17,26,29}$ High structural disorder, as evidenced by XRD and XAS in this sample, is also associated with activity in the OER. ${ }^{26,29}$ It is interesting to note that a $\mathrm{Mn}-\mathrm{Mn}(1) 2.91 \AA$ distance is somewhat longer than that observed for di- $\mu$-oxo bridged $\mathrm{Mn}$ (Iv) centres, this being typically $2.86 \AA{ }^{27,29}$ This is suggestive of the presence of a fraction of $\mathrm{Mn}(\mathrm{IV})-(\mu-\mathrm{O})_{2}-\mathrm{Mn}$ (III) contributions ${ }^{27}$ that cannot be resolved but that are consistent with the high values of Debye Waller factors obtained in our fits. It is a current hypothesis that disordered Mn oxides with valences above (III) and below (Iv) are active in OER. ${ }^{27-29,66}$ A plot of the edge position against the Mn-oxidation state for reference samples used in our XAS experiments can be used to approximate the oxidation state of Mn-centres via a linear interpolation, as previously shown in the literature. ${ }^{27,59}$ This approach shows that Mn-380 has an oxidation state intermediate between (III) and (Iv) (see Fig. S7†), again supporting the presence of defects and vacancies that result in mixed Mn-valence and contribute to OER activity. The presence of mixed Mn(III)/ $\mathrm{Mn}$ (Iv) centres in disordered and layered $\mathrm{MnO}_{2}$ oxides is known to result in slow, long-term transformations (over months/years) that result from stress release via migration of $\mathrm{Mn}$ (III) centres and cation rearrangement. ${ }^{67}$ Accordingly, we have observed similar slow transformations in the most active Mn-380, as shown by the slow appearance of additional reflections in the XRD pattern upon prolongued ageing (see Fig. S8†), which are accompanied by a reduction of activity compared to freshly prepared samples. This is not observed in the case of the least active materials, thus indicating that high OER activity is associated to a defect-rich metastable oxide phase in agreement with other oxides with reported high activity in the OER. ${ }^{68}$ Finally, the Mn-380 also exhibits the largest surface area which is also consistent with this being the most active of the oxides examined. 

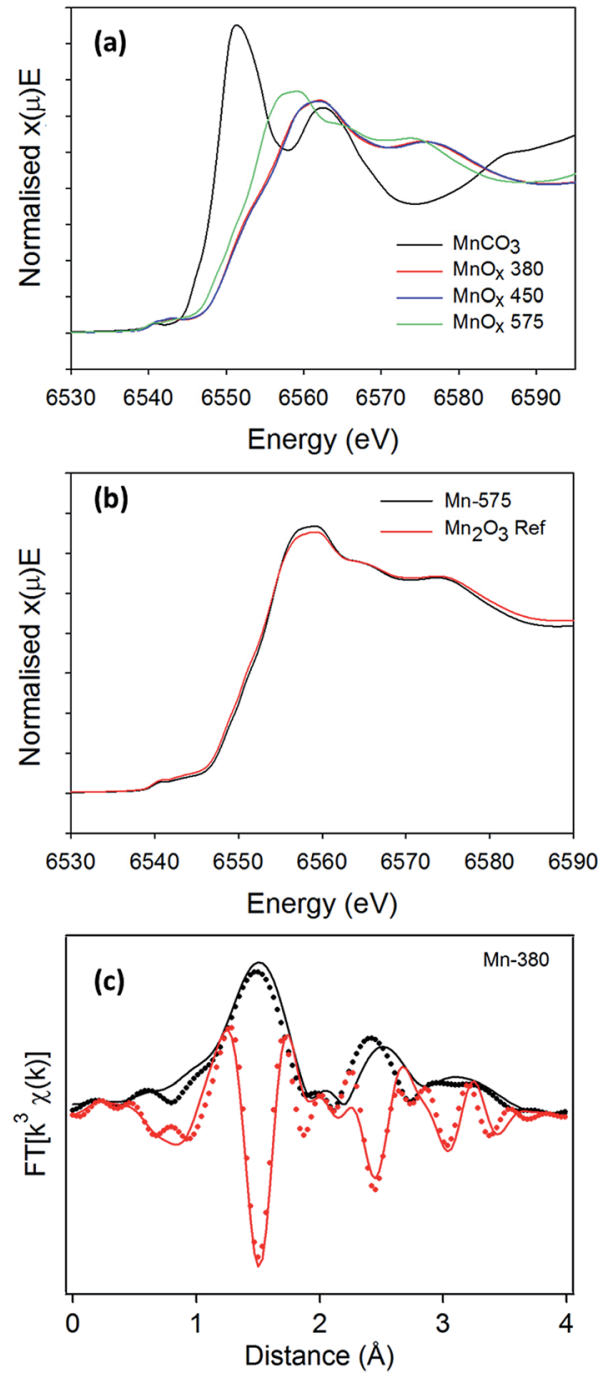

Fig. 5 (a) $\mathrm{Mn} \mathrm{K}$-edge absorption thresholds for the $\mathrm{MnCO}_{3}, \mathrm{Mn}-380$, $\mathrm{Mn}-480$ and $\mathrm{Mn}-575$ (b) XANES for the $\mathrm{Mn}-575$ with the $\mathrm{Mn}_{2} \mathrm{O}_{3}$ reference and (c) EXAFS fit (continuous lines) for the neighbors of the central $\mathrm{Mn}$ atom obtained using the $\gamma-\mathrm{MnO}_{2}$ structure for the $\mathrm{Mn}-380$ sample (dotted lines); the modulus and imaginary parts of the Fourier Transform (FT) function are reported in black and red, respectively.

Table 2 Scattering paths used for the best fit of the EXAFS spectrum of Mn-380 samples

\begin{tabular}{llll}
\hline Path & $R(\AA)$ & $N$ & $\sigma^{2}\left(\AA^{2}\right)$ \\
\hline Mn-O(1) & $1.92(1)$ & 6 & $0.008(2)$ \\
Mn-Mn(1) & $2.91(2)$ & 2 & $0.009(3)$ \\
Mn-O(2) & $3.25(3)$ & 2 & $0.04(1)$ \\
Mn-Mn(2) & $3.50(3)$ & 8 & $0.016(4)$
\end{tabular}

The Mn-450 shows a very slight increase in the amount of $\mathrm{Mn}_{2} \mathrm{O}_{3}$, based on its XRD pattern, when compared to the Mn380 and a slight decrease in the BET surface area. Samples treated in air at $575{ }^{\circ} \mathrm{C}$ are completely converted to $\mathrm{Mn}_{2} \mathrm{O}_{3}$, and the surface area also decreases drastically. From the LSV curves, a reduction in the OER performance can be observed for the

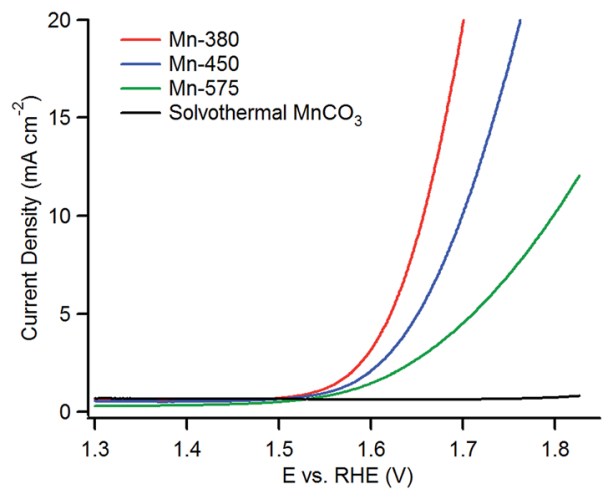

Fig. 6 Linear sweep voltammetry curves of solvothermally prepared $\mathrm{MnCO}_{3}, \mathrm{Mn}-380, \mathrm{Mn}-450$ and $\mathrm{Mn}-575$; data was collected in $1 \mathrm{M}$ $\mathrm{NaOH}$ at $5 \mathrm{mV} \mathrm{s}^{-1}$. All electrodes were fabricated by the same method with a final loading of $1 \mathrm{mg} \mathrm{cm} \mathrm{cm}^{-2}$ of the relevant material drop cast onto the substrate.

Mn-575, therefore this decrease may be linked to the decrease in surface area and the presence of $\mathrm{Mn}_{2} \mathrm{O}_{3}$ which is proposed to be less active than $\mathrm{MnO}_{2}$ phases in the OER. ${ }^{69}$

When comparing with literature values, the Mn-380 has an improved OER activity compared to the most active manganese oxide catalysts prepared by Suib et al. ${ }^{30}$ The hydrothermally produced $\alpha-\mathrm{MnO}_{2}$ oxide exhibited BET surface area values of $112 \mathrm{~m}^{2} \mathrm{~g}^{-1}$ and an overpotential value at $10 \mathrm{~mA} \mathrm{~cm}^{-2}$ of $490 \mathrm{mV}$. It is evident that the surface area of Mn-380 in this study and the $\mathrm{MnO}_{2}$ prepared by Suib et al. are similar. Hence, the overpotential decrease of $60 \mathrm{mV}$ for the Mn-380 in this study is likely attributable to the improved performance of the specific oxide phase, i.e. $\gamma-\mathrm{MnO}_{2}$ vs. $\alpha-\mathrm{MnO}_{2}$. The $\mathrm{Mn}-380$ also has improved OER capabilities when compared to other manganese oxides produced by wet chemistry methods in literature. ${ }^{2,35,40}$ This might be attributable to the manganese carbonate synthesised solvothermally in this study, which offers a robust mesoporous structure as a precursor platform for the further synthesis of the OER active Mn-380 material. Even after annealing at $380{ }^{\circ} \mathrm{C}$, the mesoporous structure can still be retained after the $\mathrm{MnO}_{2}$ phase is formed.

\section{Conclusions}

Pure manganese carbonate $\left(\mathrm{MnCO}_{3}\right)$ was obtained through a template-free solvothermal synthesis at $180{ }^{\circ} \mathrm{C}$. The manganese carbonate was used as a precursor to fabricate manganese oxides via thermal treatment in air at different temperatures. $\mathrm{XRD}$, Raman and XAS results show that a highly disordered $\mathrm{MnO}_{2}$ phase is synthesised at temperatures of $380^{\circ} \mathrm{C}$ and $450{ }^{\circ} \mathrm{C}$ while $\mathrm{Mn}_{2} \mathrm{O}_{3}$ is produced at $575{ }^{\circ} \mathrm{C}$. Interestingly, the EXAFS analysis of the sample obtained at $380{ }^{\circ} \mathrm{C}$ shows that this oxide is largely composed of $\gamma-\mathrm{MnO}_{2}$. BET analysis indicates that the highest surface area is retained for the $\mathrm{Mn}$ oxide made at $380{ }^{\circ} \mathrm{C}$, with pore sizes in the mesoporous range, while it decreases with treatment at higher temperatures.

All of the oxides were tested as catalysts for the OER and the sample prepared at $380{ }^{\circ} \mathrm{C}$ was found to exhibit the lowest 
overpotential at a current density of $10 \mathrm{~mA} \mathrm{~cm}{ }^{-2}$ of $427 \pm$ $10 \mathrm{mV}$. This performance when compared to that of oxides obtained at higher temperatures is likely due to both the high specific surface area of the material and the specific oxide phase $\left(\gamma-\mathrm{MnO}_{2}\right)$ that results from the thermal process. In conclusion, these results indicate that solvothermal synthesis of $\mathrm{MnCO}_{3}$ is a viable route for the facile synthesis of electroactive mesoporous manganese dioxide. Interestingly, the material exhibits catalytic activity in the OER that is similar to or better than other $\mathrm{MnO}_{x}$ catalysts currently in literature thus opening the possibility of a new family of low-cost OER catalysts for water splitting.

\section{Author contributions}

The manuscript was written through contributions of M. P. B, P. E. C and S. L. The concept and execution of the synthesis was carried out by S. L. XRD was carried out by S. L and M. P. B. Microscopy was carried out by S. L. XANES and EXAFS measurements were performed by M. P. B, C. D, E. F and P. E. C. Linear combination fitting and EXAFS analysis was done by $\mathrm{M}$. P. B and E. F. The electrochemistry was done by S. L and M. P. B. Raman analysis was performed by $\mathrm{H}$. N. BET and BJH was done by S. N. S. All authors have given approval to the final version of the manuscript.

\section{Funding sources}

This publication has emanated from research conducted with the financial support of the Irish Research Council via Grant No. GOIPD/2014/68 and of Science Foundation Ireland (SFI) grant No. 13/CDA/2213; MPB also acknowledges support from SFI Grant No. 12/RC/2302. We acknowledge SOLEIL for provision of synchrotron radiation facilities through Grant No. 20150740.

\section{Conflict of interest}

The authors declare no competing financial interests.

\section{Acknowledgements}

The authors are grateful to the SAMBA staff for assistance with XAS measurements and to the staff in the AML, CRANN for help with the SEM and TEM analysis, particularly D. Daly and E. McCarthy. We would also like to thank Dr B. Twamley for help with the XRD analysis. The authors would like to thank the Schmitt group in the School of Chemistry in TCD for access to their BET instrumentation. Finally, the authors are grateful to Prof. Yang Liu from the Institute of Functional Nano and Soft Materials (FUNSOM) for kindly providing the autoclaves.

\section{References}

1 S. Shafiee and E. Topal, Energy Policy, 2009, 37, 181-189.

2 M. Gong and H. Dai, Nano Res., 2015, 8, 23-39.

3 S. Cho, Y. B. Woo, B. S. Kim and J. Kim, Biomass Bioenergy, 2016, 87, 144-155.
4 Y. Cheng and S. P. Jiang, Prog. Nat. Sci., 2015, 25, 545-553.

5 M. Carmo, D. L. Fritz, J. Merge and D. Stolten, Int. J. Hydrogen Energy, 2013, 38, 4901-4934.

6 M. E. G. Lyons, R. L. Doyle, D. Fernandez, I. J. Godwin, M. P. Browne and A. Rovetta, Electrochem. Commun., 2014, 45, 60-62.

7 M. Balat, Int. J. Hydrogen Energy, 2008, 33, 4013-4029.

8 S. E. Hosseini and M. A. Wahid, Renewable Sustainable Energy Rev., 2016, 57, 850-866.

9 R. de Levie, J. Electroanal. Chem., 1999, 476, 92-93.

10 S. Trasatti, J. Electroanal. Chem., 1999, 476, 90-91.

11 C. C. L. McCrory, S. Jung, I. M. Ferrer, S. M. Chatman, J. C. Peters and T. F. Jaramillo, J. Am. Chem. Soc., 2015, 137, 4347-4357.

12 W. Hu, Y. Q. Wang, X. H. Hu, Y. Q. Zhou and S. L. Chen, J. Mater. Chem., 2012, 22, 6010-6016.

13 C. Jin, F. L. Lu, X. C. Cao, Z. R. Yang and R. Z. Yang, J. Mater. Chem. A, 2013, 1, 12170-12177.

14 B. M. Hunter, H. B. Gray and A. M. Müller, Chem. Rev., 2016, 116, 14120-14136.

15 E. Fabbri, A. Habereder, K. Waltar, R. Kotz and T. J. Schmidt, Catal. Sci. Technol., 2014, 4, 3800-3821.

16 M. P. Browne, J. M. Vasconcelos, J. Coelho, M. O'Brien, A. Rovetta, E. K. McCarthy, H. Nolan, G. Duesberg, V. Nicolosi, P. E. Colavita and M. Lyons, Sustainable Energy \& Fuels, 2017, 1, 207-216.

17 A. Indra, P. W. Menezes, I. Zaharieva, E. Baktash, J. Pfrommer, M. Schwarze, H. Dau and M. Driess, Angew. Chem., 2013, 52, 13206-13210.

18 M. P. Browne, S. Stafford, M. O'Brien, H. Nolan, N. C. Berner, G. S. Duesberg, P. E. Colavita and M. E. G. Lyons, J. Mater. Chem. A, 2016, 4, 11397-11407.

19 M. P. Browne, H. Nolan, G. S. Duesberg, P. E. Colavita and M. E. G. Lyons, ACS Catal., 2016, 6, 2408-2415.

20 J. R. Swierk, S. Klaus, L. Trotochaud, A. T. Bell and T. D. Tilley, J. Phys. Chem. C, 2015, 119, 19022-19029.

21 H. Ali-Löytty, M. W. Louie, M. R. Singh, L. Li, H. G. Sanchez Casalongue, H. Ogasawara, E. J. Crumlin, Z. Liu, A. T. Bell, A. Nilsson and D. Friebel, J. Phys. Chem. C, 2016, 120, 2247-2253.

22 S. Klaus, Y. Cai, M. W. Louie, L. Trotochaud and A. T. Bell, J. Phys. Chem. C, 2015, 119, 7243-7254.

23 J. Wang, W. Cui, Q. Liu, Z. Xing, A. M. Asiri and X. Sun, Adv. Mater., 2016, 28, 215-230.

24 E. L. Tae, J. Song, A. R. Lee, C. H. Kim, S. Yoon, I. C. Hwang, M. G. Kim and K. B. Yoon, ACS Catal., 2015, 5, 5525-5529.

25 N.-I. Kim, Y. J. Sa, S.-H. Cho, I. So, K. Kwon, S. H. Joo and J.-Y. Park, J. Electrochem. Soc., 2016, 163, F3020-F3028.

26 A. Indra, P. W. Menezes and M. Driess, ChemSusChem, 2015, 8, 776-785.

27 A. Bergmann, I. Zaharieva, H. Dau and P. Strasser, Energy Environ. Sci., 2013, 6, 2745-2755.

28 Y. Gorlin, B. Lassalle-Kaiser, J. D. Benck, S. Gul, S. M. Webb, V. K. Yachandra, J. Yano and T. F. Jaramillo, J. Am. Chem. Soc., 2013, 135, 8525-8534.

29 I. Zaharieva, P. Chernev, M. Risch, K. Klingan, M. Kohlhoff, A. Fischer and H. Dau, Energy Environ. Sci., 2012, 5, 7081-7089. 
30 Y. Meng, W. Song, H. Huang, Z. Ren, S.-Y. Chen and S. L. Suib, J. Am. Chem. Soc., 2014, 136, 11452-11464.

31 Y. Gorlin and T. F. Jaramillo, J. Electrochem. Soc., 2012, 159, H782-H786.

32 L. C. Seitz, T. J. P. Hersbach, D. Nordlund and T. F. Jaramillo, J. Phys. Chem. Lett., 2015, 6, 4178-4183.

33 M. Browne, R. J. Cullen, R. L. Doyle, P. E. Colavita and M. E. G. Lyons, ECS Trans., 2013, 53, 59-77.

34 S. Jung, C. C. L. McCrory, I. M. Ferrer, J. C. Peters and T. F. Jaramillo, J. Mater. Chem. A, 2016, 4, 3068-3076.

35 A. Ramirez, P. Hillebrand, D. Stellmach, M. M. May, P. Bogdanoff and S. Fiechter, J. Phys. Chem. C, 2014, 118, 14073-14081.

36 K. C. Neyerlin, G. Bugosh, R. Forgie, Z. C. Liu and P. Strasser, J. Electrochem. Soc., 2009, 156, B363-B369.

37 L. Xu, Q. Q. Jiang, Z. H. Xiao, X. Y. Li, J. Huo, S. Y. Wang and L. M. Dai, Angew. Chem., Int. Ed., 2016, 55, 5277-5281.

38 A. R. Zeradjanin, A. A. Topalov, Q. Van Overmeere, S. Cherevko, X. Chen, E. Ventosa, W. Schuhmann and K. J. J. Mayrhofer, RSC Adv., 2014, 4, 9579-9587.

39 X. Z. Cui, Z. L. Hua, L. S. Chen, X. H. Zhang, H. R. Chen and J. L. Shi, ChemSusChem, 2016, 9, 1010-1019.

40 C. H. Kuo, I. M. Mosa, A. S. Poyraz, S. Biswas, A. M. E-Sawy, W. Q. Song, Z. Luo, S. Y. Chen, J. F. Rusling, J. He and S. L. Suib, ACS Catal., 2015, 5, 1693-1699.

41 B. Solsona, T. Garcia, R. Sanchis, M. D. Soriano, M. Moreno, E. Rodriguez-Castellon, S. Agouram, A. Dejoz and J. M. L. Nieto, Chem. Eng. J., 2016, 290, 273-281.

42 R. D. Zhang, P. X. Li, N. Liu, W. R. Yue and B. H. Chen, J. Mater. Chem. A, 2014, 2, 17329-17340.

43 S. Y. Lian, E. Wang, Z. H. Kang, Y. P. Bai, L. Gao, M. Jiang, C. W. Hu and L. Xu, Solid State Commun., 2004, 129, 485-490.

44 M. Pudukudy, Z. Yaakob and R. Rajendran, Mater. Lett., 2014, 136, 85-89.

45 X. L. Wu, M. H. Cao, H. Y. Lu, X. Y. He and C. W. Hu, J. Nanosci. Nanotechnol., 2006, 6, 2123-2128.

46 X. C. Duan, J. B. Lian, J. M. Ma, T. Kim and W. Z. Zheng, Cryst. Growth Des., 2010, 10, 4449-4455.

47 J. L. Fernández, M. R. Gennero De Chialvo and A. C. Chialvo, J. Appl. Electrochem., 2002, 32, 513-520.

48 V. Briois, E. Fonda, S. Belin, L. Barthe, C. La Fontaine, F. Langlois, M. Ribbens and F. Villain, UVX 2010-10e Colloque sur les Sources Cohérentes et Incohérentes UV, VUV et $X$, Applications et Développements Récents, 2011, pp. 41-47.

49 B. Ravel and M. Newville, J. Synchrotron Radiat., 2005, 12, 537-541.
50 A. L. Ankudinov, B. Ravel, J. J. Rehr and S. D. Conradson, Phys. Rev. B: Condens. Matter Mater. Phys., 1998, 58, 75657576.

51 M. Newville, P. Livingšs, Y. Yacoby, J. J. Rehr and E. A. Stern, Phys. Rev. B: Condens. Matter Mater. Phys., 1993, 47, 1412614131.

52 M. Newville, J. Synchrotron Radiat., 2001, 8, 322-324.

53 C. Zhu, G. Saito and T. Akiyama, J. Mater. Chem. A, 2013, 1, 7077-7082.

54 L. Biernacki and S. Pokrzywnicki, J. Therm. Anal. Calorim., 1999, 55, 227-232.

55 K. S. W. Sing, Pure Appl. Chem., 1985, 57, 603.

56 W. Kang, D. Y. W. Yu, W. Li, Z. Zhang, X. Yang, T.-W. Ng, R. Zou, Y. Tang, W. Zhang and C.-S. Lee, Nanoscale, 2015, 7, 10146-10151.

57 S. H. Lee, Y. Kwon, S. Park, M. Cho and Y. Lee, J. Mater. Sci., 2015, 50, 5952-5959.

58 X. Tan, Y. Wan, Y. Huang, C. He, Z. Zhang, Z. He, L. Hu, J. Zeng and D. Shu, J. Hazard. Mater., 2017, 321, 162-172.

59 S. J. A. Figueroa, F. G. Requejo, E. J. Lede, L. Lamaita, M. A. Peluso and J. E. Sambeth, Catal. Today, 2005, 107108, 849-855.

60 M. Lin, B. Chen, X. Wu, J. Qian, L. Fei, W. Lu, L. W. H. Chan and J. Yuan, Nanoscale, 2016, 8, 1854-1860.

61 D. E. Simon, R. W. Morton and J. J. Gislason, Adv. X-Ray Anal., 2004, 47, 267.

62 C. M. Julien, M. Massot and C. Poinsignon, Spectrochim. Acta, Part A, 2004, 60, 689-700.

63 A. Manceau, M. A. Marcus and S. Grangeon, Am. Mineral., 2012, 97, 816.

64 C. Godart, M. Latroche, C. Freticny and C. Levy-Clement, Phys. Status Solidi A, 1992, 132, 253-268.

65 M. E. G. Lyons, R. L. Doyle, M. P. Browne, I. J. Godwin and A. A. S. Rovetta, Curr. Top. Electrochem., 2017, 1, 40-45.

66 I. Zaharieva, D. Gonzalez-Flores, B. Asfari, C. Pasquini, M. R. Mohammadi, K. Klingan, I. Zizak, S. Loos, P. Chernev and H. Dau, Energy Environ. Sci., 2016, 9, 24332443.

67 S. Grangeon, B. Lanson and M. Lanson, Acta Crystallogr., Sect. B: Struct. Sci., 2014, 70, 828-838.

68 J. A. Bau, E. J. Luber and J. M. Buriak, ACS Appl. Mater. Interfaces, 2015, 7, 19755-19763.

69 H.-Y. Su, Y. Gorlin, I. C. Man, F. Calle-Vallejo, J. K. Norskov, T. F. Jaramillo and J. Rossmeisl, Phys. Chem. Chem. Phys., 2012, 14, 14010-14022. 